\title{
ФИЗИОЛОГИЯ РАСТЕНИЙ
}

\section{ИЗУЧЕНИЕ НЕКОТОРЫХ ХАРАКТЕРИСТИК ТРАВЫ И СЕМЯН РАСТЕНИЙ ДВУХ ВИДОВ РОДА ЧЕРНУШКА - NIGELLA, ВЫРАЩЕННЫХ В УСЛОВИЯХ СОЛЕВОГО СТРЕССА}

\author{
Д.о. Гогуэ \\ Кафедра ботаники, физиологии растений и агробиотехнологии \\ Российский университет дружбы народов \\ ул. Миклухо-Маклая, 8/2, Москва, Россия, 117198
}

В статье приведены результаты изучения в сравнительном аспекте некоторых характеристик травы, плодов и семян двух видов рода чернушка - Nigella: $N$. damascena и $N$. sativa, полученных от растений, выращенных в условиях засоления. Исследовано влияние засоления на некоторые биометрические характеристики плодов и семян изученных растений, на накопление в надземной части групп БАВ и экстрактивных веществ, липидной фракции в семенах растений. Отмечено более заметное снижение содержания экстрактивных веществ в траве и липидной фракции в семенах у растений $N$. sativa. По изученным показателям более толерантными к солевому стрессу оказались растения $N$. damascena.

Ключевые слова: Nigella damascena, Nigella sativa, хлоридное засоление, трава, плоды, семена, экстрактивные вещества, биологически активные вещества, липидная фракция.

Растения рода чернушка (Nigella L.) - однолетние травянистые растения семейства лютиковые (Ranunculaceae), произрастают в Западной Европе, северной и западной Африке, Юго-Восточная и Западной Азии. Культивируются в Европе, Малой Азии и Индии. В некоторых странах СНГ выращиваются как декоративные растения, изредка дичают $[1 ; 3]$.

Самыми распространенными видами являются чернушка дамасская (Nigella damascena L.) и чернушка посевная (Nigella sativa L.). В их семенах накапливается до $40 \%$ жирного масла, содержатся сапонины, эфирное масло и липолитический фермент нигедаза. Эти растения служат источником пищевых продуктов и лекарственных веществ, а также широко используются в дизайне садов $[1 ; 3 ; 4]$.

Они могут произрастать в суровых почвенно-климатических условиях, по-видимому, благодаря специализированным механизмам устойчивости к неблагоприятным факторам среды, в том числе и к условиям солевого стресса.

По современным представлениям, негативное воздействие засоления на растение связывается как с высоким осмотическим давлением почвенного раствора, так и с токсичностью солей [2]. В таких условиях ткани растений накапливают токсичные промежуточные продукты метаболизма: диамины, путресцин и када- 
верин. При солевом стрессе в растениях подавляется образование белков и усиливается распад уже сформированных белковых комплексов. Снижение синтеза белка проявляется в заметном уменьшении скорости роста и темпов развития растений, нарушении метаболических процессов.

Цель настоящего исследования заключалась в сравнительном изучении некоторых характеристик сырья двух видов рода чернушка - Nigella, полученных от растений, выращенных в условиях солевого стресса параллельно с выращиванием в обычных условиях (контроль).

Объекты и методы исследования. Надземную часть получили от растений, выращенных в условиях контроля и при солевом стрессе (3 г NaCl/кг почвы, что считается умеренным засолением, вызывающим более или менее значительную гибель растений). Отделяли и высушивали при комнатной температуре листовки (плоды) и корни. Семена выделяли из созревших в конце вегетации плодов.

Выращивание растений осуществляли в оранжерее Института физиологии растений им. К.А. Тимирязева РАН из семян Nigella sativa L. (чернушка посевная), полученных из Египта, и из семян Nigella damascena L. (чернушка дамасская), полученных из Сирии.

Семена предварительно помещали в слабый раствор $\mathrm{KMnO}_{4}$ на 30 мин., затем проращивали в перлите в течение 15 дней, после чего молодые растения осторожно высаживали в сосуды с почвой по 8 растений на сосуд. Использовали сосуды диаметром 20 см и высотой 30 см на 4 кг воздушно-сухой почвы. Был применен 1 уровень засоления 3 г $\mathrm{NaCl}$ на кг почвы в сосуде. Вносили $\mathrm{NaCl}$ с водой, в опытах было по 2 сосуда на каждый вариант.

При исследованиях были изучены в сравнительном аспекте характеристики плодов, околоплодника и семян, а также наличие некоторых групп биологически активных веществ (БАВ) в надземной части растений двух видов чернушки, выращенных в контроле и в условиях засоления. Определение содержания экстрактивных веществ в высушенных надземных частях растений проводили с использованием 50\% этанола. Для сравнения уровня накопления липидной фракции в семенах изученных растений использовали гравиметрический экспресс-метод, который дает ориентировочное представление о содержании липидов.

Результаты исследований. Для сравнения адаптивности двух видов рода чернушки к соляному стрессу были изучены некоторые характеристики плодов, околоплодника и семян этих растений, выращенных как в контрольных условиях, так и при воздействии $\mathrm{NaCl}$. Результаты изучения представлены в табл. 1 и 2.

Таблица 1

Некоторые характеристики плодов (листовок) и семян двух видов чернушки, выращенных в контроле и в условиях засоления

\begin{tabular}{|c|c|c|c|c|c|}
\hline $\begin{array}{c}\text { Вид } \\
\text { растения }\end{array}$ & Вариант & $\begin{array}{c}\text { Число плодо- } \\
\text { листиков }\end{array}$ & $\begin{array}{c}\text { Ср. масса } \\
10 \text { плодов, мг }\end{array}$ & $\begin{array}{c}\text { Ср. число семян } \\
\text { в плоде, шт. }\end{array}$ & $\begin{array}{c}\text { Мacca } 1000 \\
\text { семян, г }\end{array}$ \\
\hline \multirow{2}{*}{$\begin{array}{l}\text { Чернушка } \\
\text { посевная }\end{array}$} & контроль & 4 & 80 & 29 & 2,60 \\
\hline & засоление & 4 & 70 & 20 & 2,35 \\
\hline \multirow{2}{*}{$\begin{array}{l}\text { Чернушка } \\
\text { дамасская }\end{array}$} & контроль & $4-5$ & 95 & 27 & 3,01 \\
\hline & засоление & $4-5$ & 88 & 23 & 2,97 \\
\hline
\end{tabular}


Вестник РУДН, серия Агрономия и животноводство, 2013, № 3

Таблица 2

Результаты изучения числа граней на поперечных срезах семян чернушки

\begin{tabular}{|l|l|c|}
\hline \multicolumn{1}{|c|}{ Вид растения } & \multicolumn{1}{|c|}{ Семена растений } & Кол-во граней на поперечных срезах семян \\
\hline \multirow{2}{*}{ Чернушка посевная } & из контрольного опыта & $3-4$ \\
\cline { 2 - 3 } & из варианта с засолением & $3-4$ \\
\hline Чернушка дамасская & из контрольного опыта & $3-5$ \\
\cline { 2 - 3 } & из варианта с засолением & $3-5$ \\
\hline
\end{tabular}

Из данных табл. 1 можно видеть при засолении тенденцию к снижению у растений исследованных видов массы плодов, числа семян в плоде и массы 1000 семян по сравнению с контрольными растениями. Исследованные характеристики для растений, выращенных в контроле, практически аналогичны таковым, приводимым для чернушек в литературе $[1 ; 3 ; 4]$. Однако число плодолистиков и масса 1000 семян для чернушки посевной в контроле и при засолении несколько меньше, чем приводится в литературе.

В литературе семена чернушек описываются как 3-гранные [1; 3; 4]. В наших опытах (см. табл. 2) на поперечных срезах семян было выявлено большее число граней. Так, в контроле и опыте семена чернушки посевной имели $3-4$ грани, а у семян чернушки дамасской наблюдалось больше граней - $3-5$.

Для определения содержания экстрактивных веществ, извлекаемых 50\% спиртом, образцы высушенной травы растений измельчали до размера частиц, проходящих сквозь сито с отверстиями размером 2 мм. Навеску сырья помещали в коническую колбу вместимостью 250 мл, прибавляли $50 \%$ спирт в соотношении 1 : 10 и нагревали при $60{ }^{\circ} \mathrm{C}$ с обратным холодильником при перемешивании на магнитной мешалке в течение 30 мин. Извлечение фильтровали через бумажный фильтр (синяя полоса) в коническую колбу. Пипеткой из фильтрата отбирали определенный объем, который помещали в фарфоровую чашку с измеренной массой и упаривали на водяной бане до сухого остатка. Чашку с остатком высушивали в сушильном шкафе при $100-105{ }^{\circ} \mathrm{C}$ до постоянной массы и вычисляли содержание экстрактивных веществ в процентах в пересчете на воздушно-сухое сырье [5].

На диаграмме (рис. 1) и в табл. 3 представлены результаты определения содержания экстрактивных веществ в надземной биомассе растений чернушки.

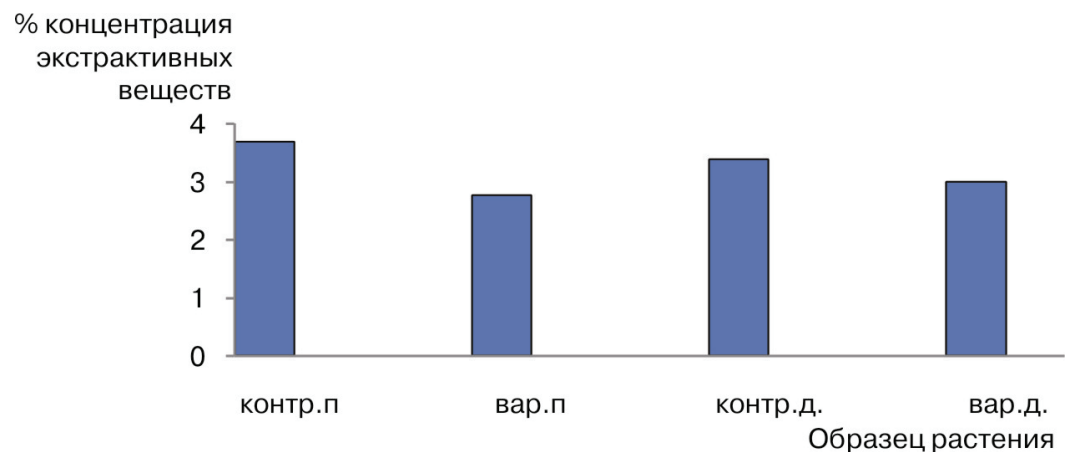

Рис. 1. Содержание экстрактивных веществ, извлекаемых 50\% спиртом, в надземной биомассе растений чернушки:

контр. - контроль, вар. - вариант с засолением, п. - чернушка посевная, д. - чернушка дамасская 
Гогуэ Д.О. Изучение некоторых характеристик травы и семян растений двух видов...

Таблица 3

Уровни накопления экстрактивных веществ, извлекаемых 50\% спиртом, в надземных частях двух видов чернушки

\begin{tabular}{|c|c|c|c|c|c|c|}
\hline $\begin{array}{l}\text { Название } \\
\text { растения }\end{array}$ & $\begin{array}{c}\text { Вариант } \\
\text { опыта }\end{array}$ & $\begin{array}{l}\text { Навеска } \\
\text { сырья, г }\end{array}$ & $\begin{array}{c}\text { Объем } \\
\text { экстрагента, } \\
\text { мл }\end{array}$ & $\begin{array}{c}\text { Объем упа- } \\
\text { ренного } \\
\text { фильтрата, мл }\end{array}$ & $\begin{array}{c}\text { Масса су- } \\
\text { хого остат- } \\
\text { ка, г }\end{array}$ & $\begin{array}{c}\text { Концентрация } \\
\text { веществ в из- } \\
\text { влечении, \% }\end{array}$ \\
\hline \multirow{2}{*}{$\begin{array}{l}\text { Чернушка } \\
\text { посевная }\end{array}$} & контроль & 4,00 & 40 & 18 & 0,67 & 3,70 \\
\hline & засоление & 6,54 & 70 & 25 & 0,69 & 2,76 \\
\hline \multirow{2}{*}{$\begin{array}{l}\text { Чернушка } \\
\text { дамасская }\end{array}$} & контроль & 3,95 & 40 & 10 & 0,34 & 3,40 \\
\hline & засоление & 3,24 & 40 & 10 & 0,30 & 3,00 \\
\hline
\end{tabular}

Для обнаружения возможного наличия некоторых групп БАВ в высушенной надземной части опытных растений было проведено тестирование водных извлечений общепринятыми в фармакогнозии качественными реакциями [6]. На наличие фенольных соединений проводили реакцию с раствором хлорида железа (III). Наличие полисахаридов (слизей) устанавливали на основании реакции с 0,1 молярным раствором $\mathrm{NaOH}$ и после смешивания водного извлечения с 95\% этиловым спиртом в соотношении 1: 3 .

Выявление наличия сапонинов проводили с использованием методики пенообразования при разных $\mathrm{pH}$ в водном извлечении. Наличие в водных извлечениях из сырья флавоноидов определяли по цианидиновой пробе, с раствором щелочи и раствором алюминия хлорида. Результаты определения групп БАВ в высушенной траве двух видов чернушки, выращенных в контрольном опыте и в условиях засоления, представлены в табл. 4 и 5. Количество знаков «+» указывает на результаты визуальной оценки степени образования осадков и интенсивности окрашивания растворов после реакции.

Таблица 4

Результаты определения групп БАВ в надземной части чернушки посевной, выращенной в условиях засоления и в контроле

\begin{tabular}{|c|c|c|c|c|c|c|c|c|}
\hline \multirow{3}{*}{$\begin{array}{c}\text { Объект } \\
\text { изучения }\end{array}$} & \multicolumn{8}{|c|}{ Реактивы и условия проведения качественных реакций } \\
\hline & \multirow{2}{*}{$\begin{array}{c}\text { раствор } \\
\text { хлорида } \\
\text { железа }\end{array}$} & \multirow{2}{*}{$\begin{array}{c}\text { раствор } \\
\mathrm{NaOH}\end{array}$} & \multicolumn{3}{|c|}{ пеннообразование } & \multirow{2}{*}{$\begin{array}{c}\text { раствор } \\
\text { хлорида } \\
\text { алюминия }\end{array}$} & \multirow{2}{*}{$\begin{array}{c}95 \% \\
\text { спирт }\end{array}$} & \multirow{2}{*}{$\begin{array}{c}\text { цианиди- } \\
\text { новая } \\
\text { проба }\end{array}$} \\
\hline & & & $\begin{array}{l}\text { в нейтр. } \\
\text { среде }\end{array}$ & $\begin{array}{l}\text { в ще- } \\
\text { лочн. } \\
\text { среде }\end{array}$ & $\begin{array}{l}\text { в кислой } \\
\text { среде }\end{array}$ & & & \\
\hline $\begin{array}{l}\text { Трава } \\
\text { чернушки } \\
\text { посевной } \\
\text { (соль) }\end{array}$ & $\begin{array}{l}\text { слабое } \\
\text { черное } \\
\text { окраши- } \\
\text { вание + }\end{array}$ & $\begin{array}{l}\text { желтое } \\
\text { окраши- } \\
\text { вание }\end{array}$ & $\begin{array}{l}\text { обиль- } \\
\text { ная и ус- } \\
\text { тойчи- } \\
\text { вая пена }\end{array}$ & \begin{tabular}{|l} 
желтое \\
окраши- \\
вание, \\
быстро \\
исчза- \\
ющая \\
пена + \\
\end{tabular} & $\begin{array}{l}\text { устойчи- } \\
\text { вая пена }\end{array}$ & $\begin{array}{l}\text { светло- } \\
\text { коричне- } \\
\text { вое окра- } \\
\text { шивание }\end{array}$ & $\begin{array}{l}\text { образо- } \\
\text { вание } \\
\text { неболь- } \\
\text { шого } \\
\text { аморф- } \\
\text { ного } \\
\text { осадка + }\end{array}$ & $\begin{array}{l}\text { слаборо- } \\
\text { зовое } \\
\text { окрашива- } \\
\text { ние + }\end{array}$ \\
\hline $\begin{array}{l}\text { Трава } \\
\text { чернушки } \\
\text { посевная } \\
\text { (контроль) }\end{array}$ & $\begin{array}{l}\text { черное } \\
\text { с зеленым } \\
\text { оттенком } \\
\text { окрашива- } \\
\text { ние ++ }\end{array}$ & $\begin{array}{l}\text { желтое } \\
\text { окраши- } \\
\text { вание }\end{array}$ & $\begin{array}{l}\text { обиль- } \\
\text { ная и ус- } \\
\text { тойчи- } \\
\text { вая пена }\end{array}$ & \begin{tabular}{|l} 
желтое \\
окраши- \\
вание, \\
быстро \\
исчза- \\
ющая \\
пена ++
\end{tabular} & $\begin{array}{l}\text { устойчи- } \\
\text { вая пена }\end{array}$ & $\begin{array}{l}\text { светло- } \\
\text { коричне- } \\
\text { вое окра- } \\
\text { шивание + }\end{array}$ & $\begin{array}{l}\text { образо- } \\
\text { вание } \\
\text { аморф- } \\
\text { ного } \\
\text { осадка ++ }\end{array}$ & $\begin{array}{l}\text { слаборо- } \\
\text { зовое } \\
\text { окрашива- } \\
\text { ние ++ }\end{array}$ \\
\hline $\begin{array}{l}\text { Группа } \\
\text { БАВ }\end{array}$ & \multicolumn{2}{|c|}{$\begin{array}{l}\text { Фенольные } \\
\text { соединения }\end{array}$} & $\begin{array}{l}\text { Сапо- } \\
\text { нины }\end{array}$ & \multicolumn{2}{|c|}{$\begin{array}{c}\text { Кислые тритерпе- } \\
\text { новые сапонины }\end{array}$} & $\begin{array}{l}\text { Флаво- } \\
\text { ноиды }\end{array}$ & $\begin{array}{l}\text { Полиса- } \\
\text { хариды }\end{array}$ & $\begin{array}{l}\text { Флаво- } \\
\text { ноиды }\end{array}$ \\
\hline
\end{tabular}


Из данных табл. 4 видно, что в условиях засоления и в контроле (без соли) в траве присутствуют те же группы БАВ, однако, судя по обилию образования осадков и интенсивности окрашивания продуктов реакций, в водном извлечении из травы растений контрольного опыта накапливается больше БАВ, чем в биомассе чернушки посевной, подвергшейся солевому стрессу.

В надземных частях чернушки дамасской, выращенной в условиях засоления и в контроле (без соли), было обнаружено наличие одних и тех же групп БАВ. По степени образования осадков и интенсивности окрашивания растворов продуктов качественных реакций больше БАВ накапливаются в биомассе растений в контроле, чем в биомассе чернушки дамасской, выращенной в условиях засоления.

Результаты изучения массы семян чернушки, выращенной в условиях контроля в сравнении с таковой у семян чернушки, вегетация которой прошла в условиях солевого стресса, в разрезе двух видов представлены в табл. 6. В ней приведены массы 10 шт. семян испытуемого растения, которую вычисляли путем взвешивания от каждого опыта в 6 повторностях.

Изучение массы 10 шт. семян показывает, что независимо от вида чернушки масса семени растений, выращенных в контроле, превышает массу семени растений, испытавших при вегетации солевой стресс. Однако можно предположить, что чернушка дамасская в отношении накопления массы своих семян более устойчива к засолению, чем чернушка посевная. В первом случае разница между контролем и вариантом опыта составляет около $1 \%$, а во втором — гораздо больше около $10 \%$.

Таблица 5

Результаты определения групп БАВ в надземной части чернушки дамасской, выращенной в условиях засоления и в контроле

\begin{tabular}{|c|c|c|c|c|c|c|c|c|}
\hline \multirow{3}{*}{$\begin{array}{c}\text { Объект } \\
\text { исследо- } \\
\text { вания }\end{array}$} & \multicolumn{8}{|c|}{ Реактивы и условия проведения качественных реакций } \\
\hline & \multirow{2}{*}{$\begin{array}{c}\text { раствор } \\
\text { хлорида } \\
\text { железа }\end{array}$} & \multirow{2}{*}{$\begin{array}{c}\text { раствор } \\
\mathrm{NaOH}\end{array}$} & \multicolumn{3}{|c|}{ пеннообразование } & \multirow{2}{*}{$\begin{array}{c}\text { раствор } \\
\text { хлорида } \\
\text { алюми- } \\
\text { ния }\end{array}$} & \multirow[t]{2}{*}{ 95\% спирт } & \multirow{2}{*}{$\begin{array}{c}\text { цианиди- } \\
\text { новая } \\
\text { проба }\end{array}$} \\
\hline & & & $\begin{array}{l}\text { в нейтр. } \\
\text { среде }\end{array}$ & $\begin{array}{l}\text { в ще- } \\
\text { лочн. } \\
\text { среде }\end{array}$ & $\begin{array}{l}\text { в кис- } \\
\text { лой } \\
\text { среде }\end{array}$ & & & \\
\hline $\begin{array}{l}\text { Трава } \\
\text { чернуш- } \\
\text { ки да- } \\
\text { масской } \\
\text { (соль) }\end{array}$ & \begin{tabular}{|l|} 
черное \\
с зелено- \\
ватым \\
оттенком \\
окраши- \\
вание и \\
осадок ++
\end{tabular} & $\begin{array}{l}\text { желтое } \\
\text { окраши- } \\
\text { вание }\end{array}$ & $\begin{array}{l}\text { обиль- } \\
\text { ная и ус- } \\
\text { тойчивая } \\
\text { пена }\end{array}$ & $\begin{array}{l}\text { желтое } \\
\text { окраши- } \\
\text { вание, } \\
\text { быстро } \\
\text { исчеза- } \\
\text { ющая } \\
\text { пена } \\
\end{array}$ & $\begin{array}{l}\text { обиль- } \\
\text { ная и } \\
\text { устой- } \\
\text { чивая } \\
\text { пена }\end{array}$ & $\begin{array}{l}\text { светло- } \\
\text { корич- } \\
\text { невое } \\
\text { окраши- } \\
\text { вание }\end{array}$ & $\begin{array}{l}\text { образование } \\
\text { аморфного } \\
\text { осадка ++ }\end{array}$ & $\begin{array}{l}\text { слабое } \\
\text { розовое } \\
\text { окрашива- } \\
\text { ние }++\end{array}$ \\
\hline $\begin{array}{l}\text { Трава } \\
\text { чернуш- } \\
\text { ки да- } \\
\text { масская } \\
\text { (конт- } \\
\text { роль) }\end{array}$ & \begin{tabular}{|l} 
черное \\
с зелено- \\
ватым \\
оттенком \\
окраши- \\
вание и \\
осадок \\
+++ \\
\end{tabular} & \begin{tabular}{|l} 
желтое \\
окраши- \\
вание
\end{tabular} & $\begin{array}{l}\text { средней } \\
\text { интен- } \\
\text { сивности } \\
\text { пена }\end{array}$ & $\begin{array}{l}\text { желтое } \\
\text { окраши- } \\
\text { вание, } \\
\text { быстро } \\
\text { исчеза- } \\
\text { ющая } \\
\text { пена }\end{array}$ & $\begin{array}{l}\text { обиль- } \\
\text { ная и } \\
\text { устой- } \\
\text { чивая } \\
\text { пена + }\end{array}$ & $\begin{array}{l}\text { светло- } \\
\text { корич- } \\
\text { невое } \\
\text { окраши- } \\
\text { вание + }\end{array}$ & $\begin{array}{l}\text { образование } \\
\text { большого по } \\
\text { объему } \\
\text { аморфного } \\
\text { осадка ++++ }\end{array}$ & $\begin{array}{l}\text { розоватое } \\
\text { окрашива- } \\
\text { ние }++++\end{array}$ \\
\hline $\begin{array}{l}\text { Группа } \\
\text { БАВ }\end{array}$ & \multicolumn{2}{|c|}{$\begin{array}{l}\text { Фенольные } \\
\text { соединения }\end{array}$} & $\begin{array}{l}\text { Сапо- } \\
\text { нины }\end{array}$ & \multicolumn{2}{|c|}{$\begin{array}{c}\text { Кислые тритерпе- } \\
\text { новые сапонины }\end{array}$} & $\begin{array}{l}\text { Флаво- } \\
\text { ноиды }\end{array}$ & $\begin{array}{c}\text { Полисаха- } \\
\text { риды }\end{array}$ & $\begin{array}{l}\text { Флаво- } \\
\text { ноиды }\end{array}$ \\
\hline
\end{tabular}


Гогуэ Д.О. Изучение некоторых характеристик травы и семян растений двух видов...

Таблица 6

Масса семян двух видов чернушки при выращивании в условиях контроля и солевого стресса (мг, в навеске по 10 семян)

\begin{tabular}{|c|c|c|c|c|}
\hline \multirow{2}{*}{ Повторность } & \multicolumn{3}{|c|}{ Вид чернушки и вариант опыта } \\
\cline { 2 - 5 } & \multicolumn{2}{|c|}{ Чернушка дамасская } & \multicolumn{2}{c|}{ Чернушка посевная } \\
\cline { 2 - 5 } & контроль & засоление & контроль & засоление \\
\hline 1 & 3,06 & 2,90 & 2,79 & 2,18 \\
\hline 2 & 2,99 & 3,05 & 2,55 & 2,25 \\
\hline 3 & 3,04 & 3,10 & 2,83 & 2,15 \\
\hline 4 & 2,99 & 2,89 & 2,87 & 2,70 \\
\hline 5 & 2,90 & 2,97 & 2,19 & 2,43 \\
\hline 6 & 3,05 & 2,95 & 2,28 & $2,35 \pm 0,16$ \\
\hline
\end{tabular}

Для сопоставления влияния условий засоления на накопление липидной фракции в семенах двух видов чернушки, выращенных в разных вариантах опыта, было проведено гравиметрическое определение сырого жира в семенах опытных растений экспресс-методом. Для этого около 0,4 г семян помещали в фарфоровую ступку и пестиком тщательно растирали так, чтобы не оставалось цельных семян. Измельченный материал количественно переносили в плоскодонную колбу со шлифом вместимостью 150 мл, заливали порцией по 20 мл н-гексана (марки «Хч» по ТУ 2631-006-29483781-2008). Содержимое колбы нагревали на водяной бане с обратным холодильником после начала кипения растворителя в течение 15 мин. После охлаждения при комнатной температуре извлечение фильтровали через бумажный фильтр (синяя лента) в круглодонную колбу со шлифом вместимостью 50 мл с доведением до постоянной массы. Растворитель полностью удаляли на вакуум-ротационном аппарате при температуре $50{ }^{\circ} \mathrm{C}$ с остаточным давлением 0,2 атм. Потом колбу с маслянистым остатком помещали в сушильный шкаф при температуре $100-105{ }^{\circ} \mathrm{C}$ и выдерживали в течение 30 мин., затем помещали для охлаждения в эксикатор. После охлаждения в эксикаторе определяли массу липидной фракции и рассчитывали ее содержание в семенах на воздушносухое сырье.

На диаграмме (рис. 2) представлены результаты сопоставления содержания липидной фракции в семенах двух видов чернушки.

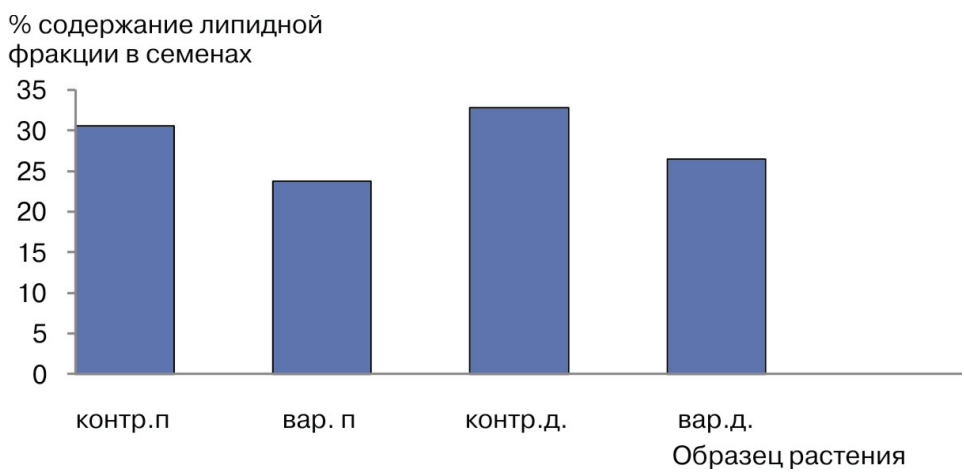

Рис. 2. Уровни содержания липидной фракции в семенах двух видов чернушки, прошедших вегетацию в разных условиях

(обозначения те же, что на рис. 1) 
Как видно из диаграммы (см. рис. 2), уровень накопления липидов семенами чернушки посевной, выращенной на почве с солевой нагрузкой, меньше $(23,75 \%)$, чем в контроле (30,52\%). В семенах чернушки дамасской, выращенной на почве без солевой нагрузки, также накапливается больше липидной фракции $(32,83 \%)$, чем в семенах растений, выращенных в условиях солевого стресса $(26,45 \%)$. Таким образом, в условиях засоления образование липидной фракции в семенах обоих видов чернушки тормозится одинаково, примерно на 20\%.

Таблица 7

\begin{tabular}{|l|l|c|c|c|c|}
\hline \multirow{2}{*}{ Растения } & \multicolumn{1}{|c|}{$\begin{array}{c}\text { Вариант } \\
\text { опыта }\end{array}$} & $\begin{array}{c}\text { Масса } \\
\text { семян, г }\end{array}$ & $\begin{array}{c}\text { Объем } \\
\text { извлечения, мл }\end{array}$ & $\begin{array}{c}\text { Масса липидной } \\
\text { фракции, г }\end{array}$ & $\begin{array}{c}\text { Содержание липид- } \\
\text { ной фракции, \% }\end{array}$ \\
\hline \multirow{2}{*}{$\begin{array}{l}\text { Чернушка } \\
\text { дамасская }\end{array}$} & контроль & 0,402 & 25,0 & 0,132 & 32,83 \\
\cline { 2 - 5 } & засоление & 0,412 & 25,0 & 0,109 & 26,45 \\
Чернушка & контроль & 0,416 & 25,0 & 0,127 & 30,52 \\
\cline { 2 - 6 } & засоление & 0,400 & 25,0 & 0,095 & 23,75 \\
\hline
\end{tabular}

\title{
ЛИТЕРАТУРА
}

[1] Крашенинников И.M. Род 514. Чернушка - Nigella // Флора СССР. В 30 т. / Гл. ред. акад. В.Л. Комаров. - М.; Л.: Изд-во АН СССР, 1937. — Т. VII. - Ред. тома Б.К. Шишкин. C. $62-72$.

[2] Кузнецов Вл.В., Дмитриева Г.А. Физиология растений. - М.: Абрис, 2011.

[3] Кораблева О. Целительница чернушка // Огородник. - 2008. - № 8. - С. 10-12.

[4] Атлас лекарственных растений России. - М.: Щербинская типография, 2006. — С. 323.

[5] Государственная фармакопея. - Изд. XI. — Вып. 1. - М.: Медицина, 1987.

[6] Фитохимический анализ лекарственного растительного сырья: Методические указания к лабораторным занятиям / К.Ф. Блинова (ред.). — СПб.: СПХФА, 1998.

\section{STUDYING OF SOME CHARACTERISTICS OF A GRASS AND SEEDS OF TWO SPECIES OF NIGELLA RECEIVED FROM PLANTS, GROWN UP IN THE CONDITIONS OF A SALT STRESS}

\author{
D.O. Goguè
}

Department of botany, plant physiology and agrobiotechnology

People's Friendship University of Russia

Miklukho-Maklaya str., 8/2, Moscow, Russia, 117198

In article results of studying are given in comparative aspect of some characteristics of a grass and seeds of two species of Nigella: $N$. damascena and $N$. sativa received from plants, grown up in the conditions of salinization. Influence of salinization on some biometric characteristics of fruits and seeds of the studied plants, on accumulation in elevated part of BAV groups and extractive substances, lipidic fraction in seeds of plants is investigated. More noticeable decrease in the content of extractive substances in a grass and lipidic fraction in seeds at $N$. sativa plants is noted. On the studied indicators $N$. damascena plants appeared more tolerant to a salt stress.

Key words: Nigella damascena, Nigella sativa, chloride salinization, grass, fruits, seeds, extractive substances, biologically active agents, lipid fraction. 
Гогуэ Д.О. Изучение некоторых характеристик травы и семян растений двух видов...

\section{REFERENCES}

[1] Krasheninnikov I.M. Rod 514. Chernushka - Nigella // Flora SSSR. V 30 t. / Gl. red. akad. V.L. Komarov. — M.; L.: Izd-vo AN SSSR, 1937. — T. VII. — Red. toma B.K. Shishkin. — S. $62-72$.

[2] Kuznecov Vl. V., Dmitrieva G.A. Fiziologija rastenij. — M.: Abris, 2011.

[3] Korableva O. Celitel'nica chernushka // Ogorodnik. - 2008. - № 8. - S. 10-12.

[4] Atlas lekarstvennyh rastenij Rossii. — M.: Shherbinskaja tipografija. - 2006. - S. 323.

[5] Gosudarstvennaja farmakopeja. - Izd. XI. - Vyp. 1. - M.: Medicina, 1987.

[6] Fitohimicheskij analiz lekarstvennogo rastitel'nogo syr'ja: Metodicheskie ukazanija k laboratornym zanjatijam / K.F. Blinova (red.). — SPb.: SPHFA, 1998. 